\title{
A review of the researches on WeChat
}

\author{
Jinfang YAN \\ School of Graduate \\ Tianjin University of Sport \\ Tianjin,300381,China
}

\begin{abstract}
In recent years, the development of WeChat received extensive attention of the academic circles, and the research on WeChat had made important progress in several ways. Research from the fundamental of WeChat, the transmission mechanism of WeChat, the influence of WeChat on college students' social and some comparative research between and weibo, the traditional media with WeChat, the current development of WeChat public platform, we reviewed related research results from these six aspects. So as to provide reference for later related research and put forward the inadequacy of current development of WeChat public platform, the development problems, and try to find ways to resolve it.
\end{abstract}

Keywords- WeChat; WeChat public platform; Review; Development

\section{INTRODUCTION}

For two or three years, WeChat as mobile social software, with its own advantage, grabbed the public's attention rapidly, and it's kind of a comprehensive infiltration and changes people's habits and customs. According to the relevant department statistics, from January 2011 the first version of WeChat came out to the beginning of 2014, WeChat users in China have more than 600 million. At present, WeChat has covered more than 200 countries and regions in the world, more than 270 million active users at home and abroad. WeChat public accounts in the last 15 months grew to more than 200, and keep every 8000 growth rate, and more than one hundred million times of information interaction. At the same time, the development of the WeChat has been received extensive attention of the academic circles, the research on WeChat had made important progress in several aspects, this article is to review related research results, so as to provide reference for future further research and reference.

\section{THE CONNOTATION AND DEVELOPMENT CONDITION} OF WECHAT

WeChat (English name: WeChat) is a free instant messaging service program which can be applied to intelligent terminal published by Tencent. Users can across different communication operators and operating system platform with little network flow to send free voice messages, video, images and text quickly. In addition, you can share data streaming media content. WeChat also have functions and services such as "wave", "bottle", "friends", "platform", "public speech notepad" and so on. Since WeChat has many advantages, the time when it received widely recognition it developed rapidly as well. In August 2013, WeChat overseas edition number of registered users hit 100 million, 100 million daily active users. In January 2014, WeChat adds taxi function provided by taxi "drops" within the products. Then, WeChat become a big business trading platform. WeChat have gone abroad, and the function is still expanding.

\section{THE CLASSIFICATION OF WECHAT}

We can find paper topics directly named for WeChat more than 200 articles in the Chinese academic journals online. In general, topics or point of view about these papers and researches are following six kinds:

\section{A. basic researches relates to WeChat}

When it comes to WeChat we have to mention Kik. On October 19, 2010, Kik Messenger appeared on App Store and Android Market. Kik is a local phone directory, establish the connection with contacts directly, and on this basis, it is an IM social software that can realize free text message, call purikura, and individual state synchronization function through the information push technology. On January 21, 2011, Tencent formally issued WeChat, which is similar to Kik. As for the characteristics of WeChat, academic circles generally think that WeChat is a kind of social tool. Both Xinzhou Xie and Jing An believe that: "WeChat is a social tool with high degree of privacy and has the core of relationship. Zhen Tan think: "WeChat is such software that committed to build the 'wet' relationship between people and rely on the combination of social soft wares, and creates a "wet " environment of the social network. The reasons why people use some kind of media is because it has the function of meeting the needs of people. And WeChat is widely used because it satisfied people's need better than other media. In terms of the functional design of WeChat, it initially designed for the convenience for people to contact for acquaintances, that is to say by voice intercom people can communicate with their QQ friends and friends in mobile phone address book directly, help users build a strong relationship connection network. But in order to bring new move to the user, and to meet various needs of users, WeChat launched "shake" and "people nearby" 'bottles "and other functions. The appearance of these functions let WeChat becomes stronger and stronger" In a word, WeChat plays an active role in nowadays China spreading platform, WeChat is a strong force in the field of China. 


\section{B. The research on the transmission mechanism of WeChat}

Both Xingdong Fang and Yansheng Shi think: From the perspective of communication, the transmission of WeChat focuses on point-to-point personal communication. There are three kinds of transmission modes involved in WeChat. One is spreading between friends. It is a point-to-point bidirectional communication between users by adding friends. The sources come from mobile phone mail lists, QQ friends, and some strangers. The second is spreading through circles of friends, that is to say by adding the plug-in circle of friends, people can receive their own circle of friends dynamic through mobile phone, and they can send pictures to circles of friends. Transmission range related to the number of their friends. The last is information received, on the premise of the plug-in installation; people refer WeChat as the information source and can receive news from Tencent website push and information from public accounts push, etc.

Yang Li thinks: the spreading scope of WeChat mainly among friends, the spreading content is blocked to strangers, and only circles of friends can see. Its own set of multiple WeChat information diffusion barriers weakened communication ability as a public platform, determines that it's unable to form a multi-level chain spread as weibo do.

To sum up, the spreading of WeChat mainly among friends, point-to-point spread, point to point, the transmission range is narrow, and unable to form a multi-level chain. But this does not influence the development of WeChat.

\section{The WeChat influence on college students' social}

Jing Xu thinks: WeChat as a relatively new social tool not only meets the characteristics of college students' pursuit of novelty, but also has its rich social content, it can expanding the scope of its social and spreading social message which has positive influence quickly, these effects attract more students to join the WeChat. But its potential negative effects cannot be ignored. It makes students have WeChat dependence, and excessive indulge in a closed space. Also it misleads college students' cognition and personality in social. It may lead to college students individual rights been infringed in social.

Zhen Zhai thinks: WeChat makes college students' social information transmission become more convenient and faster. WeChat enriches college students' social content. But WeChat can make college students have social cognitive biases in social, conducive to the formation of college students' personality. College students will indulge in WeChat. The openness of WeChat can make the college students' individual rights be infringed when social.

Overall, at the same time WeChat brings convenience to college students it also brings questions that are difficult to overcome in the short term. However, we are still optimistic for the development of WeChat.

\section{The research comparison between weibo and WeChat}

Yidan Jia thinks, compared with weibo, WeChat information transmission coverage is low. In terms of communication content, WeChat pay more attention to release of personal emotion, while weibo prefers to show social phenomenon. WeChat has advanced communication means, and it has mobility and real-time performance. At the same time, the micro blog shows naked information openness, while WeChat is restricted to information dissemination. In terms of the number of published information, WeChat public accounts can publish only one piece of news within 24 hours, but weibo can release news without limitation, at any time or any place.

Yongdong Chen thinks the more open the weibo push is, the more accurate the WeChat push. The both ways are complementary. Weibo mainly receive the information from followed people and transferred information, be @ information and personal messages. WeChat received messages from circles of friends, one-on-one information, and news issued by public accounts. The two ways to receive messages are complementary. In addition, the way of spreading information is complementary also.

In general, weibo is strong on media properties, while WeChat is stronger on social attribute. The two complement each other, are mutually complementary relationship.

\section{E. Research on traditional media to WeChat}

Yanxia Chen believes that the traditional media need to test WeChat because more and more new media is gradually changing the channels that people receive information, it gives the traditional media great sense of crisis. The powerful support of WeChat creates the opportunity for traditional media. WeChat realized the combination of audiences' virtual social circle and practical circle, broken weibo's weak relationship of chain transmission mode, powerful features play an important role in the process of disseminate information, makes the traditional media preempted the market of WeChat. On one hand, the low threshold reduces the cost of traditional media. Media spend small amount of time on WeChat public platform and just certain regular maintenance, they can easily push news, which save a lot of production costs. On the other hand, the information transmission is two-way choice. Compared with the traditional media, WeChat gives audience more independent options; in terms of information transmission, it is realized the two-way choice of ideal transmission form, and enhance the information rate of reading. In addition, the strong interactions promoted audience viscous properties. The important thing that WeChat is different from other new media platforms is the ability to interact with the user privately and timely, the characteristics of the interactive media makes it's better to maintain and strengthen the relationship with audience.

Yuxi Jin and Yan Zhang both believe what WeChat brings to traditional media is independent user, the numbers are huge and have distinctively personalities, through WeChat, traditional media can better meet the demand of the user's preferences, and at the same time users can choose useful information more freedom and more convenient.

However, Haihua Chen believes that the traditional media participate in WeChat operation did not get high transmission rate and high exposure as expected. Just some enterprises take advantage of WeChat and successful in marketing and promotion. 
In a word, with the increase of WeChat users, traditional media have to attaches great importance to the development of WeChat as one of the new media; traditional media must borrow the strength of new media. But traditional media must follow the rules of its spread, keep content innovation, and keep the user's attention.

\section{F. Research on the status quo of the development of WeChat public platform}

Shirui Fu thinks: WeChat public platform is a new function module that Tencent put forward based on WeChat. Through this module, individuals and enterprises can create WeChat public account. It will mainly face to the celebrities, the government, the media, and institutions that launched cooperation to promote business, the features include a mass of information push, auto reply, one-on-one communication, etc.

Jing Zhao etc. think: now there are four main kinds of domestic WeChat public platform. One is public media platform. They are highly active in current public platform, and have prominent influence. Its operation mainly includes four categories: First, the portal channels. Second, print media and radio media. Third, independent technology media. Fourth, We-media. The second type is brand public service platform. WeChat point-to-point privacy of communication can meet the demands from domestic and foreign. The third class is public service platform. Such as governments, public institutions, non-profit organizations, colleges and universities and more and more public service institutions join WeChat. The fourth category is electronic commerce public platform. Electronic commerce public platform operates mainly in $\mathrm{B} 2 \mathrm{C}$ electrical contractor and social guidance electrical contractor. Such as dangdang, jingdong mall and beautiful said. At present, E-Commerce in the public platform mainly focuses on the traffic guidance, after-sales service, maintenance of customer relationships, etc.

\section{CONCLUSIONS}

At present, WeChat public platform development in China is not mature, also has many problems in the process of development. WeChat has almost one hundred percent of delivery rate, but has not been widely applied to all walks of life. For example, our country can use its powerful delivery rate and utilization rate to improve the national quality education. Public schools can use WeChat platform to create their public account, to give students ideological education and daily English learning education, etc.

WeChat public platform also has many problems in the process of development. For example: WeChat public accounts are homogeneity serious, and some WeChat public accounts send same contents,. WeChat public accounts have poor interactivity, what users basically do are reading the news pushed by platform, they can't participate in discussions and rarely share.
There's no deny that WeChat is booming in recent years. But to better serve the society, it remains to be further researched.

\section{References}

[1] Dong Guangan Liu Siyang. "Double micro" anomie and countermeasures in the field of environment public mobile network [J]. Photocopying of National People's Congress, 2014, (10).

[2] Government affairs WeChat be included in the Chinese government website performance evaluation index [EB/OL]. (2013-11-29) [201312-01]. HTTP: / / WWW. Techweb.com.cn/internet/2013-1129/1364115.shtml.

[3] di di taxi function is added to the WeChat Pay the fare can use WeChat. Tencent technology

[4] ShenXing. WeChat time: Tencent supremacy [J]. Road enterprise research. The 2011-09

[5] xie xinzhou, quiet. Transmission characteristics of WeChat and its social influence [J]. Chinese media technology, 2013 (6): 21-23.

[6] Tan Zhen. The effect of the traditional media how to use WeChat to expand - letter of medium function and the impact analysis [J]. Chinese reporters, 2013 (5) : 101-102.

[7] FanChangZhi, wang yong, xiao-ling tang. Communication application tutorial [M]. Changsha: hunan people's publishing house, 2008.

[8] Li Aihui, li Yang. Survey on social function of WeChat [J]. Journal of youth press, 2013 (27) : 37-38.

[9] fang xingdong, stone now, etc. The WeChat transmission mechanism and governance issues research [J]. Modern communications, 2013, 6 .

[10] Li Yang WeChat dissemination mechanism behind the interpersonal mode change analysis [J]. Journal of jianghan BBS, in May 2014.

[11] Xu Jing. WeChat's influence on college students' social [J]. Journal of news propagation, 2013.2.

[12] ZhaiZhen. Introduction to the WeChat's influence on college students' social [J]. Journal of communication.

[13] Jia Yidan. Under the background of new media fusion weibo and contrastive analysis of the WeChat [J].

[14] yong-dong Chen. WeChat as for weibo: are complementary rather than replace [J]. Journal of news and writing, 04 period in 2013

[15] Yan-xia Chen. Causes and status quo of traditional media to WeChat [J]. Journal of media observation, 2014.9.

[16] Jinyu, zhang yan. There is WeChat, more authority - the theory of traditional media how to borrow LiWei letter [J]. Journal of hunan mass media vocational technical college, in July 2013.

[17] hai-hua Chen. Try to talk about predicament of traditional media borrow LiWei letter [J]. Journal of news propagation, 2013.3.

[18] to pay the general theory, WeChat public platform in the TV media development [J]. Journal of film and television media

[19] Zhao Jing, li bei. WeChat public platform development status of a preliminary study [J]. Journal of news practice, 2013, 8 .

[20] He lu xia, He Honghua. The era of big data "WeChat" public platform for the development of opportunities and challenges [J]. Journal of news propagation, 2014, 5 .

[21] Janice yeung, the media ecological environment under the perspective of WeChat platform transmission [J]. Journal of public media e era, $2014,8$.

[22] Simon wang fei to kam, namely the WeChat, weibo still cannot be replaced, from "the horse boat lost plane incident" said spread out [J]. Press, 2014, 4. 